ESTUDIO CRÍTICO

Hispania, LVII/2, nưm. 196 (1997)

\title{
LA GUERRA DE DON RICARDO Y OTRAS GUERRAS
}

\author{
por \\ JULIO ARóSTEGUI \\ Universidad Carlos III, Getafe
}

\begin{abstract}
A la memoria de Manuel Tuñón de Lara, calumniado, amigo y maestro
\end{abstract}

En el año de 1996 se cumplía, como es bien sabido, el sexagésimo aniversario del comienzo de la guerra civil española de 1936. La efemérides no ha pasado desapercibida para la publicística especializada ni para los medios de comunicación. Pero lo más espectacular de todo es que sesenta años parecen ser plazo suficiente para que el libelista más conocido de la España actual, don Ricardo de La Cierva, pueda presentar un libro acerca de la guerra en el que, según su título, se hallarian "todos los problemas resueltos". Ciento ochenta y ocho años desde la Guerra de la Independencia, ciento sesenta y tres desde la primera carlista y casi cien desde la de Cuba, no han bastado para que nadie con la mínima honestidad y cordura pueda decir que tiene resueltos todos los problemas. ¿Cómo es que Don Ricardo ha podido realizar tan descomunal hazaña concediéndose sólo sesenta? La respuesta es difícil, pero cabe sospechar, por lo que después diremos, que puede hallarse si se sigue una cierta pista: don Ricardo nos engaña...

En todo caso, el eco de este nuevo aniversario decenal no puede compararse ni de lejos con el que tuvo el cincuentenario de aquel acontecimiento en 1986. Pero nuestro comentario bibliográfico de lo aparecido ahora es conveniente que comience con una referencia, a efectos comparativos, al menos, con lo que ocurrió entonces.

El cincuentenario del comienzo de la guerra civil española que se conmemoró en 1986 nos pareció a muchos que, con la ocasión que dio a variadas formas de revisión del episodio central de nuestra historia en el siglo $\mathrm{xx}$, había plantado unos jalones de los que difícilmente podría volverse atrás en el futuro. Parecía entonces ciertamente que los grandes enfrentamientos puramente ideológicos a los que la guerra había dado lugar desde siempre estaban realmente si no resueltos, sí en vías claras de resolverse.

Sin duda, el cincuentenario de la guerra civil en 1986 fue un momento de importancia en la historia de la historiografía de la guerra civil espa- 
ñola '. Pero la importancia de esa fecha no estriba tanto en la producción nueva de obras, aunque las hubo, como en lo que tuvo la reflexión de recapitulación general del problema histórico e historiográfico, ideológico y político de la guerra. Por vez primera se pudieron entonces dedicar abundantes y variadas manifestaciones científicas, culturales o artísticas a la rememoración de la guerra - que no «conmemoración», como alguien ha dicho malignamente que se hizo entonces, pues es cierto que una guerra civil no es algo a conmemorar- cuando las circunstancias históricas ligadas a ella, como era el propio Régimen que engendró, habían desaparecido.

La vuelta de la libertad política a España permitió todo tipo de actos, publicaciones, reediciones en el interior del país de obras mucho tiempo prohibidas. Se pudo hacer uso importante de la historia oral, cuando todavía era tiempo, de la recreación visual y de variados testimonios de personas que vivieron la tragedia ${ }^{2}$. El cincuentenario parecía una ocasión excepcional para una revisión global del significado de la guerra y de su posición en la memoria histórica de los ciudadanos. Esa revisión fue realizada en buena parte, con notable eco en los medios de comunicación, en los académicos y algo menos en los políticos. Es bien cierto, sin embargo, que no puede decirse, por razones variadas que podemos omitir aquí, que la ocasión fuese enteramente aprovechada.

Es verdad que el espíritu del cincuentenario parecía plenamente propicio para una visión superadora de forma definitiva del tipo de diferencias y conflictos sociales que la guerra representó y que han pervivido mucho tiempo en la memoria hasta condicionar, se ha dicho, la propia marcha política de la transición posfranquista ${ }^{3}$. La proporción de personas que había vivido la guerra y que aún permanecían vivas en 1986 no llegaba al $20 \%$ de la población. Era ya momento, por tanto, para detenerse en el análisis de la influencia de la memoria colectiva y de las trayectorias biográficas relacionadas con la guerra civil en la política y las mentalidades de la épocas de la transición posfranquista. La posición superadora y hasta conciliadora pareció, de cualquier forma, triunfar plenamente en el mundo académico, en el de la cultura, los

\footnotetext{
I Algunos recuentos de lo que significó la actividad publicista en aquel momento se hicieron ya en eł mismo año. Aunque no es el único, véase la revista ARBOR, CXXV, 491-492, noviembrediciembre 1986 con el texto Crónica del cincuentenario, de Jesús Martínez. Más recientemente, véase el largo estudio historiográfico de la bibliografía de la guerra civil desde 1975 a la actualidad que hace Juan A. Blanco, Veinte años de historiografia de la guerra civil española, 1975-1995, en la publicación bibliográfica que comentamos después.

2 Prácticamente, cada uno de los volúmenes mensuales en que se publicó la Historia de la Guerra Civil editada por la revista Historia 16 contenia un testimonio de un testigo o protagonista de primera fïla.

3 He aquí que en este año de 1996 aparece un libro sobre esa memoria, el de Paloma AgulLAR FERNÁNDEZ: Memoria y olvido de la guerra civil española, Madrid, Alianza Editorial, 1996, que si bien no es un libro enteramente satisfactorio, no merece las críticas que le dedica el Prof. Javier Tusell en su recensión en el diario El País, aquejada, como casi todas las de este colega, por el problema de no leer suficientemente los libros que critica.
}

Hisprania, LV[1/2, núm. 196 (1997) 777-787 
medios de comunicación, el arte y la política y, en definitiva, en la gran masa de la opinión.

Pero he aquí que diez años después parece preciso reconocer, con toda la humildad que sea precisa, que nos hemos equivocado en toda regla. Los hechos son tozudos... El pleito ideológico de la guerra civil, aunque con mucha menos trascendencia social y política a medida que transcurren los años y decenios, dista de estar resuelto y si bien en muchas ocasiones no emerge de forma explícita, es cierto que subyace en otras muchas manifestaciones de fuertes discordancias ideológicas. Pero la cuestión central que aquí importa es otra.

Los oportunistas de casi siempre parece que tienen especial aprecio a las efemérides reseñables cada decena de años y no han dejado pasar la ocasión de los «sesenta años». Sobre la guerra civil española ha aparecido de nuevo un cierto ramillete de publicaciones bajo la cobertura de ese sexagésimo aniversario. Son de diversa catadura y de calidad muy dispar y de ellas ofrecemos un pequeño recuento en nota al pie ${ }^{4}$. Pero lo que cabe

4 Aunque nuestro comentario estricto no va a referirse a todas ellas, ni pretendemos que aparezca aquí absolutamente todo lo publicado, las obras que hemos tenido en cuenta incluyen, a nuestro juicio, aquello que es reseñable, y de las que queremos hacer mención aquí, son:

BIHES, Biblografias de Historia de España, La guerra civil, 1936-1939, Madrid, CINDOC, Consejo Superior de Investigaciones Científicas, 1996, 2 vols.

De la CJerva, R., Historia esencial de la guerra civil española. Todos los problemas resueltos sesenta años después, Madrid, Editorial Fénix, 1996, 822 págs.

BerCNeKER, W., Guerra en España, 1936-1939, Madrid, Editorial Sintesis, 1996, 191 págs.

TÉmiMe, E., La guerre civile espagnole. Un événement traumatisme, Bruxelles, Complexe, 1996, 223 págs.

PAYNE, S. G. y TUSELL, J. (dirs.), La guerra civil. Una nueva visión del conflicto que dividió España, Madrid Temas de Hoy, 1996, 654 págs.

MALEFAKIS, E. (dir.), La guerra de España (1936-1939), Madrid, Taurus, 1996, 679 págs.

Preston, P. y MaCKenzie, A. L. (eds.), The Republic Besieged, Civil War in Spain 1936-1939, Edinburgh University Press, 1996, 324 págs.

La guerra civil, Barcelona, Editorial Folio, 1996 (en fascículos mensuales).

MoRadiellos, E., La perfidia de Albión. El gobierno británico y la guerra civil española, Madrid, Siglo XXI, 1996, 408 págs.

Tuñon de LARA, M.; Miralles, R; Garcia Chico B., Juan Negrín López, el hombre necesario, Las Palmas, Gobierno de Canarias, 1996, 246 págs.

RAguer, H., El general Batet, Barcelona, Ediciones Península, 1996, 407 págs.

CARDONA, F., y otros, La guerra militar, Madrid, Historia 16, 1996-1997, 5 vols.

PaZ, A., Durruti, Madrid, Fundación Anselmo Lorenzo, 1996.

SCOTT-Ellis, R, Diario de la guerra civil española, Barcelona, Plaza y Janés, 1996, 325 págs.

VAQUEZ RIAL, H., La guerra civil española. Una historia diferente, Barcelona, Planeta, 1996, 325 págs.

VIDAL, C., La guerra de Franco. Historia militar de la guerra civil española, Barcelona, Planeta, 1996, 587 págs.

RojAs, C., Momentos estelares de la guerra civil, Barcelona, Plaza y Janés, 1996, 321 págs.

A estas publicaciones más o menos normalizadas podrian añadirse algunas otras de divulgación e ilustración casi folklóricas hechas por prolifícos autores sobre todo tipo de temas, incluidos los novelistas de ocasión, Díaz-Plaja, Tusell, Pons Prades, ętc., a las que carece de interés referirse aquí.

Hispunia, LVII/2, núm. 196 (1997) 777-787 
señalar es que las obras en las que se aprecia claramente $-\mathrm{y}$ no es difícil hacerlo- que son de aprovechamiento coyuntural de una efemérides son de un tipo general muy especial, por no decir otra cosa, y no tienen casi nada que ver, por no decir que nada en absoluto, con la honesta investigación de la Historia...

El excelente estudio introductorio que Juan A. Blanco ha puesto a la publicación de una nueva recopilación bibliográfica sobre la historiografía de la guerra civil ${ }^{5}$, deja perfectamente claro que ni el interés historiográfico sobre el asunto ni el engrosamiento constante de la bibliografía dedicada a ella han decaído un ápice. Lo que ocurre es que el año 1996 ha añadido a este interés académico, verdaderamente serio, el interés social, y el mercantil, sin duda, de tratarse de una efemérides decenal. No es extraño que, una vez más, ciertas voces sardónicas y poco avisadas desde luego, hayan clamado contra esta supuesta "saturación de memoria" y se hayan preguntado si hemos de esperar tener la misma fiesta cada diez años.

En 1996 han vuelto a repetirse los dossiers de prensa que fueron abundantes en 1986. Ahora, sin embargo, se trata sólo de cuadernillos rememorativos, no de series, como los publicados por los diarios de Madrid, El País, EI Mundo y ABC. Se ha republicado una obra con muchos colaboradores, y sin duda de gran calidad y variedad de aportaciones, en entregas mensuales, que ya apareció en 1986, la de la revista Historia 16, publicada de nuevo ahora por la Editorial Folio sin introducir en ella la más mínima actualización ${ }^{6}$. Caso bien distinto es la publicación nueva que ha dirigido Edward Malefakis para la Editorial Taurus y que contiene convenientemente actualizados por los autores y con una presentación también inédita los textos que aparecieron en la serie de El País en 1986. La honestidad editorial queda asegurada al hacerse constar este hecho en el volumen.

Una nota crítica como la presente acerca de la bibliografía de la guerra civil, centrándola en lo aparecido en 1996, está obligada a discriminar entre publicaciones de real alcance historiografico, es decir, aquellas que de una u otra manera, directo o indirecta, pero relacionada siempre con el firmante del texto, reflejan investigaciones empíricas, de aquellas otras que son meras recopilaciones de segunda mano, con ánimo claramente divulgativo o mercantil. De este tipo serían obras como las de Horacio Vázquez Rial, César Vidal o Carlos Rojas de las que nos limitaremos a su sola mención. En otros casos nos encontramos ante republicaciones sin modificaciones, como la de la biografía de Durruti hecha por Abel Paz. Aparece un nuevo diario de guerra, el de la aristócrata y enfermera británica Priscila Scott-Ellis, y nuevas versiones de algún libro en otra lengua, como es el caso de la obra de Dom Hilari Raguer sobre el general Batet cuya versión catalana era anterior. Los comentarios los reduciremos a lo más significativo de todo ello.

\footnotetext{
\$ En BIHES, La guerra civil, 1936-1939, o.c., págs. 7 y ss.

* Para no repetir las notas a pie de página, véanse las fichas bibliográficas de cada una de las obras que citamos en el recuento general de la nota 4 .

Hispanis, LVli/2, nüm. 196 (1997) 777-787
} 
Previamente, la amplia difusión que tienen los dossiers de prensa obliga a dedicarles unos párrafos. Lo primero que cabe señalar es que mientras diarios como El País y $\mathrm{ABC}$ han echado mano para su confección de especialistas y profesores que vuelven a la carga con consideraciones académicas y eruditas, de mayor o menor interés, novedad, profundidad y sesgo ideológico - que de todo hay-, el diario El Mundo se decantó por la evocación pseudo-literaria, donde los periodistas hacen de literatos, los literatos hacen de ensayistas y los ensayistas se convierten en especialistas en el tema, quedando todo ello más cerca del ridículo que de otra cosa. Pero los dossiers de prensa, y otros textos que se han originado como consecuencia de ellos, o los artículos de circunstancias aparecidos también presentan el interés añadido de reflejar especialmente esa vuelta a la distorsión ideológica de la guerra que hemos comentado y en la que, desde luego, el diario $\mathrm{ABC}$ que es, de otra parte, el que mayor número de artículos ha publicado, tiene la palma.

De alguna manera, estos dossiers y los demás textos de prensa vuelven a presentar dos imágenes distintas de la guerra, aunque no sería enteramente justo decir que vuelven a los términos de una guerra de «los vencedores» y otra «de los vencidos», aunque las cosas apunten por ahí. De hecho, relacionado con esos dossiers, un columnista de $\mathrm{ABC}$ como Federico Jiménez Losantos emplea explícitamente tal lenguaje en un texto al que aludiremos después. El espíritu del cincuentenario aparece aquí claramente conculcado, desapareciendo enteramente aquella tensión hacia la visión «superadora" y haciendo acto de presencia en ciertas versiones periodísticas los bandos en guerra como cuestión viva. La prensa reflejó también posiciones acerca de la trascendencia social, política y académica de la «memoria» de la guerra, su persistencia y su abuso, como muestra, todo ello, de que las efemerides decenales siguen siendo ocasión de polémica.

De algún meandro de esta polémica ha sido objeto directo el autor mismo de esta nota y como no sería elegante detenerse aquí en ello me limito al comentario ? Es inexcusable, sin embargo, citar el por todos los conceptos extraordinario artículo sobre el reflejo de la guerra civil en el sexagésimo aniversario de su comienzo, en la prensa y fuera de ella, publicado por Alberto Reig en la revista SISTEMA, en el que se trata adecuadamente del papel de la prensa y los columnistas ${ }^{8}$. Como señala Reig, en ciertos medios el insulto o la calumnia ha vuelto a sustituir al debate.

De las obras de conjunto sobre la guerra civil aparecidas en este años lo menos que cabe señalar es una importante diversidad en su concepción y enfoque, lo que propicia una oferta bibliográfica variada y con diversos niveles de-profundidad para cubrir la exigencias de un público lector también

\footnotetext{
7 Véase la columna de F. Jiménez Losantos «La villanía», $A B C$, 19 de julio de 1996, que es un comentario del texto de Julio Arostegut en el dossier publicado en El País, 14 de julio de 1996, Véase también la carta al director de $\mathrm{ABC}$ dèl autor, publicada -mutilada, claro-, en ese periódico el 9 de agosto de 1996.

8 REIG, A., Memoria viva y memoria olvidada de Ta.guerra civil, Sistema, Madrid, 136, enero de 1997, págs. 27-41.
}

Hispania, LVIU/2, núm. 196 (1997) 777-787 
diversificado. Hay que señalar como característica dominante en la historiografía del año 1996 que no ha aparecido ninguna nueva verdadera historia de la guerra como producto colectivo, al contrario de lo ocurrido en 1986, aunque sí producto de algún autor. En todo caso, deberíamos hablar primero de una obra bibliográfica, publicada por un centro oficial, lo que seguramente redundará en una peor distribución comercial, cuya importancia no hay peligro de exagerar. Nos referimos a La guerra civil (1936-1939), dentro de la colección de Bibliografías de la Historia de España (BIHES) que lleva a cabo el Centro de Información y Documentación Científica (CINDOC), del Consejo Superior de Investigaciones Científicas, bajo la coordinación de M. ${ }^{a}$ Cruz Rubio Liniers.

Desde el punto de vista científico, este instrumento de trabajo para especialistas es lo mejor que ha producido el año; pero ya se sabe que en este país lo mejor no es lo más conocido, ni celebrado, ni valorado, sino más bien todo lo contrario. Con esta publicación, que añade importantes novedades técnicas, la bibliografía de la guerra civil se haya recogida ya en catálogos que cubren el espacio 1936-1995, con la salvedad del período 1968-1975.

Las obras colectivas de conjunto aparecidas son de desigual porte. La dirigida por Edward Malefakis es, a pesar de ciertas colaboraciones temáticas, una obra de episodios de la guerra que han escrito, sin duda, los mejores especialistas existentes en 1986 y vivos hoy, con la triste excepción de Ramón Salas Larrazábal. Los episodios presentados siguen una línea cronológica intercalando entre ellos tratamientos temáticos acerca de la revolución, la Iglesia o la represión, presentando el conjunto más completo de todas las obras aparecidas. Es lo más cercano a una historia convencional de la guerra y ni que decir tiene que serf́a muy difícil encontrar un elenco más serio de autores sobre el tema. Ello no obstante, la obra resulta un híbrido entre historia secuencial e historia temática y probablemente no es apta para desconocedores absolutos del tema. Figura entre lo mejor que hay en el mercado.

Otras son las características de la publicación colectiva dirigida por Payne y Tusell. Para empezar, estamos otra vez ante un texto concebido como explicación sistemática; no es, pues, una "historia" de la guerra, sino un conjunto de ensayos sobre aspectos diversos. Tras una exposición general hecha por Payne sobre "Antecedentes y crisis de la democracia", siguen trabajos sobre temas muy generales, la historia militar, económica, internacional, la evolución política de los bandos, la revolución social, la represión y la cultura. Fal. tan algunos importantes y tampoco es obra apta para no iniciados. El elenco de autores es variado y hasta pintoresco y refleja, sin duda, afinidades, amistades o parentescos de los directores. Junto a especialistas en la guerra civil conocidos y serios, como Alpert, Bernecker y Sole i Sabaté, o historiadores de la economía como Palafox, aparecen allí otros nombres cuya justificación puede que conozcan sólo los directores.

La obra es, pues, sumamente irregular y su aportación escasa. El marco general que presenta Stanley Payne tiene todas las trazas de las posiciones hartamente conservadoras de este autor, si bien su «sabe estar" hace que se encuentren lejos de la apologíarde posiciones de extrema derecha que aparece 
en otros textos suyos. Su exposición de la vida republicana es vulgar. Por lo demás, decir que los alzados pretendían "una república autoritaria de derechas", pág. 96, es lo que se esperarfa oír de este autor, es decir, un desatino. Pero donde la cosa brilla a más altura es en la elección de un tal George Esenwein para que nos cuente «El Frente Popular: la polftica republicana durante la guerra civil». Algo así como si nos presentáramos ante el verdugo para que nos ajusticie aportando nosotros el hacha... Esenwein, anticomunista feroz y convencido, de la Hoover Institution, no tiene, que yo conozca, otros créditos científicos para tratar de semejante e importante asunto que ser el amigo y albacea de Burnett Bolloten y, en consecuencia, afín a los directores de esta obra.

El colectivo dirigido por Preston y Mackenzie, no traducido, no es tampoco una historia de la guerra sino un clásico reading que distribuye su materia en dos grandes partes, de interés evidente, las que llaman «La hostilidad internacional hacia la Segunda República» y "La forja de un esfuerzo de guerran. Los colaboradores son, por lo general, de calidad. Además del propio Preston, figuran Moradiellos, Smyth, Helen Graham y el veterano Southworth, entre otros. La temática es de interés en todos los casos. Graham escribe sobre Negrín, Preston sobre Mussolini, Richards sobre le violencia y la construcción del franquismo, etc.

Pero no cabe duda que el texto más apasionante, el documentado con la minucia a que nos tiene acostumbrados, y el más divertido es el de $\mathrm{H}$. $\mathrm{R}$. Southworth, titulado "The Grand Camouflage": Julian Gorkin, Burnett Bolloten and the Spanish Civil Warn. En él, el viejo Southworth vuelve a sus demonios familiares y sigue desvelándonos mitos sobre la guerra, «camuflajes" y mentiras, en aras del anticomunismo. Resulta que no sólo la obra firmada por El Campesino titulada "Comunista en España y antiestalinista en la URSS» fue escrita en realidad por Julian Gorkin como panfleto anticomunista, sino que detrás de ello estaba jBurnett Bolloten! Nadie sabe lo que eran capaces de maquinar los guerreros de la guerra fría. Southworth vuelve a poner a Bolloten en su sitio, bien distinto de aquel en que le pone la ignorancia y el cinismo de Don Ricardo de la Cierva ${ }^{9}$ y a mostrar las profundas deter. minaciones políticas básicas de su obra.

Entre las obras de autores personales cabe una referencia a las de Walther L. Bernecker, Émile Témime y R. de la Cierva, aunque esta última, dada la orientación de esta Nota hacia obras serias, sea referenciada sólo por razones que explicitaremos después. Bernecker y Témime, ambos extranjeros, son especialistas en la historia española, en la guerra civil, justamente, autores de importantes obras publicadas anteriormente. Mientras Témime elabora un texto de síntesis destinado a público no español, no traducido al castellano, con estructura clásica, que es una puesta a punto más breve de

9 En absoluto debe deducirse de lo que digo que yo no reconozca el valor en muchos aspectos de la última versión de la obra de Burnett Bolloten, incomparable por todos los conceptos con las de sus amigos $y$ afines. 
ciertos planteamientos que fueron expuestos muchos años antes en una publicación conjunta con Pierre Broué ${ }^{10}$, Bernecker nos presenta un texto "sistemático", aparecido previamente en alemán, y no propiamente una secuencia histórica: guerra militar, internacional, polstica, económica, etc. Para mi gusto personal esto disminuye la utilidad de este texto que no su calidad, aunque la obra se enriquece con importantes y útiles anexos sobre desideratas de la investigación, guías de instrumentos de trabajo y bibliografía muy actualizada.

Llegamos así a la Historia esencial de la guerra civil española que escribe don Ricardo de la Cierva en la que, según su autor, se hallan "todos los problemas resueltos sesenta años después" y que suena acaso como, y pretende representar exactamente igual que, aquella que se empezaba a escribir cincuenta y seis años antes y que se tituló Historia de la Cruzada Española, cuyo autor clave fue Joaquín Arrarás. Pero con una diferencia: aquella historia oficial del franquismo era y es, aunque falsa, útil. La obra con la que De la Cierva celebra el sesenta aniversario es sólo lo primero, una falsedad casi desde su primera página, en la que, por cierto, se dice que muchas de las deformaciones de la guerra "persisten en nuestro tiempo en forma de mentiras" ". De ello no existe mejor prueba que su propio libro.

Las obras de don Ricardo, catedrático jubilado de la Universidad española, antiguo funcionario del Ministerio de Información y Turismo (época de Franco), ex ministro, publicista inagotable y agotador, autor de numerosos libros panfletarios en la línea de la extrema derecha, fundador de editorial propia donde ahora los produce, presentan una seria dificultad para ser serenamente juzgadas, dificultad que reside donde seguramente no sospechan muchas personas, entre ellas sus lectores más adictos: la de su pétrea, imperturbable e indesglosable pertinacia. La obra de De la Cierva carece de matices, de altibajos y de concesiones. Ello hace que tenga que ser enteramente dejada de lado por disparatada e inutilizable ${ }^{12}$-que es lo que hacen la totalidad de los especialistas en sus cabales, aunque cometen el error de no denunciarlao minuciosamente desmontada en todas las falsedades que contiene. Por desgracia, ninguna de estas dos sesudas alternativas es la que podemos adoptar aquí, y por ello hay que limitarse a unos breves comentarios.

10 Broué, P.; TÉmIME, E., La revolución y la guerra en España, México, Fondo de Cultura Económica, 1977, 2 vols. La versión original francesa apareció en 1961 y jamás fue permitida en España. Sus posiciones eran abiertamente antifranquistas y muy favorables a ląs visiones urevolucionarias» de la guerra en la línea anarquista o poumista, debido, sobre todo, a los planteamientos de P. Broué. Témime dice ahora explicitamente que él no tiene nada de lo que renegar respecto a esa obra, pero reconoce que en ella habia lagunas y errores de detalle.

11 O.c., pág. V.

12 Es de absoluta justicia reconocer que hay dos textos de De la Cierva, o inspirados por él, cuyo interés no puede negarse: uno es la Bibliografia publicada en 1968, otro el inacabado que se titulaba Historia de la guerra civil española, de la que sólo apareció un volumen publicado por la Editorial San Martín que no pasaba de los precedentes, pero que era muy aprovechable en lo referente a los orígenes de la guerra en la Ropública de preguerra.

Hispenia, LVIL/2, ním. 196 (1997) 777-787 
Además de las incontables disgresiones e incongruencias de este nuevo libelo, en el que se empieza hablando de Aznar, González, las elecciones de 1996 y la memoria histórica, para despotricar de todo ello, las falsedades de De la Cierva son poliédricas, aunque tienen dos caras esenciales, tal vez por su carácter mismo de «historia esencial». Unas atañen a las tesis históricas que el libro contiene; otras a las falsedades de hecho. Hemos de limitarnos a un ejemplo de cada una de ellas. Respecto de lo primero, la más increible muestra de cinismo intelectual aparece en el planteamiento hecho de que fue el stablishment republicano, los servidores de la República, los que verdaderamente declararon la guerra ${ }^{13}$. Esta culpabilidad de la República es una tesis explícita a veces e implícita en todo el texto. Pero hay otras igual de falsas.

Las falsedades de hecho, las calumnias incluso, como la de atribuir sin más a Carrillo, y sin pruebas, la responsabilidad de los asesinatos de Paracuellos, son inumerables en todo el texto. El Sr. De la Cierva es un hábil manipulador y falsificador de textos como ya demostré a propósito de su delirante libro "Agonía y Victoria» ${ }^{4}$, pero, además, ni siquiera parece conocer la bibliografía reciente o, sencillamente, la oculta. Acabaremos con un solo dato más.

El coronel Segismundo Casado expuso en un conocido libro testimonial sobre su sublevación contra el gobierno de la República, el 5 de marzo de 1939 en Madrid ${ }^{15}$, que la razón que le movió a ello fue el "golpe de estado" que preparaba Negrín nombrando para el mando del Estado Mayor y de todas las grandes agrupaciones del Ejército republicano a los principales jefes militares comunistas, Cordón, Modesto, Líster, El Campesino y Tagüeña, y que esos nombramientos se publicaron en el Diario Oficial del Ministerio de Defensa del 4 de marzo de 1939, del que nadie habra visto ningún ejemplar nunca, seguramente porque el propio Casado, por lo que sabemos, los habia secuestrado.

En efecto, hoy se han encontrado ejemplares de ese Diario donde no aparece ninguno de los nombramientos de que hablaba Casado. Tal cosa la sabemos desde 1989, y el descubrimiento lo han hecho, además de Michael Alpert, ¡Burnett Bolloten, el autor anticomunista más admirado de Don Ricardo, del que se ha constituido en gran defensor, y al que ni siquiera ha leído o no cree en 1996 (?)! ${ }^{16}$. Esta inmensa falsedad de De la Cierva, que sigue manteniendo que hubo una conspiración comunista, se contiene en su parágrafo «Un golpe de Estado en el Diario Oficial», en el que habla de esos nombramientos y en el que se refiere al «Diario Oficial de 4 de marzo, cuya existencia consta documentalmente pero del que se destruyeron todos los ejemplares», página $778 \mathrm{del}$

13 Véase en especial el capitulo $6 .^{\circ}$ «La declaración de guerra».

14 Reseña en Diario 16.

15 CasAdo, S., Así cayó Madrid. Úlimo episodio de la guerra civil, Madrid, Guadiana de Publicaciones, 1967. Escrito en Londres su primera versión fue la inglesa.

16 Bolloten da cuenta de este hallazgo y de su importancia en La guerra civil española: revolución y contrarrevolución, Madrid, Alianza Editorial, 1989. Véase el parágrafo «En busca de culpablesn págs. 1039 y ss. y especialmente la página 1045 . 
libro que comentamos. ¿Puede juzgar el lector después de estas muestras quién es Don Ricardo de La Cierva? ${ }^{17}$

Nos queda un comentario final sobre algunas monografías de sustancial interés aparecidas también en este año. Además del escrito excelente y minucioso de Raguer sobre el general Batet, ajusticiado por los sublevados, y del de Cardona, con otros textos añadidos, sobre la guerra de ejércitos, un resumen muy útil, queremos fijarnos especialmente en el de Tuñón, Miralles y García Chico sobre Negrín y en el de Moradiellos sobre la política británica.

Respecto del primero de ellos es preciso insistir en que la figura de Negrin seguía estando necesitada de estudios que sacaran al personaje de la "ciénaga de las descalificaciones», como hemos dicho en otro lugar. La interpretación de la obra de Negrín empieza a cambiar en los libros, artículos y conferencias últimamente dedicados a él (trabajos de Santiago Alvarez, Moradiellos, Graham, etc.) Entre ellos figura éste que, sin aportar elementos documentales nuevos, que probable y significativamente no existen por más que la familia aparente poseerlos, reivindica una visión política de Negrín superadora del viejo y estúpido dicterio de su sumisión a Moscú. La obra contiene de manera novedosa un análisis de la tarea científica de Negrín como fisiólogo.

Moradiellos ha vuelto en un nuevo libro, más amplio y completo, al tema de la posición británica sobre la guerra española en lo que constituye el mejor estudio que poseemos sobre el asunto. Si antes se había centrado especialmente en la posición británica ante la sublevación, el nuevo texto, «La perfidia de Albión", se dedica a estudiar todo el espacio de la guerra. La documentación británica empleada es prácticamente exhaustiva y la conclusión, algo blanda, se cifra en que «los gobernantes británicos juzgaron el sacrificio de una España "roja" como un precio razonable por la codiciada amistad italiana y la alusión de preservar la paz en Europa. Y por ello aceptaron la victoria de la España "blanca" con plena consciencia de sus riesgos y la esperanza de poder domeñarlos». Conclusión plausible pero excesivamente indulgente.

$$
* * *
$$

Como dicen Payne y Tusell en la conclusión de su libro, sobre la guerra civil española se ha escrito incansablemente y se lo seguirá haciendo en el siglo que viene. Creemos que las interpretaciones de la guerra renovarán continuamente en el futuro. Una pléyade de investigadores jóvenes han acudido y seguirán acudiendo al reclamo de un tema que sigue conservando la misma fascinación para su estudio, por más que haya cesado el interés público, que tenía antes. Las gentes jóvenes saben ya poco de la guerra, se dice. Como es natural, podríamos añadir. Lo mismo que saben poco de Franco, de Azaña, de

17 Unas fotografias reproduciendo el Diario aparecieron en el articulo de Michael Alpert publicado en Historia J6, número 185 de 1991 sobre la sublevación de Casado.

Hispania, LVI1/2, núm. 196 (1997) 777-787 
los carlistas y de Napoleón, de todo aquello que no han vivido. Es natural también. Pero la guerra civil sigue y seguirá siendo un tema central en la ciencia de la Historia de España y del mundo.

Es difícil que la supuesta magia de los aniversarios decenales, intereses mercantiles y oportunismo publicístico aparte, pueda concitar por sí sola la aparición de obras decisivas sobre la guerra. No hay que extrañarse; éstas obedecen poco a las efemérides. El año 1996 ha producido alguna buena monografía, nos ha procurado un nuevo instrumento bibliográfico, pero casi nada como nueva interpretación de conjunto. No hay que asombrarse tampoco de ello. La investigación paciente está reñida con los libros de circunstancias.

Hay que lamentar sólo dos realidades presentes. Una es la pretensión de ciertos "invitados" al tema de pontificar sobre cosas sabidas. Esto ocurre en alguno de los libros de conjunto señalados y en casi todas las obras de divulgación publicadas. Hay quienes como el también inevitable en estas ocasiones señor don Carlos Rojas pretenden, con soberano mal gusto sólo comparable con el reconocido mal gusto asimismo de sus editores, que una guerra civil puede tener momentos estelares y titulan así un libro. Otros autores son simples plumiferos.

Lo peor es que en este tema tengamos todavía que referimos a gentes con la suficiente estulticia y con la infinita, provocativa y cómica petulancia de creer que pueden tener "todos los problemas resueltos" acerca de cualquier Historia. Se trata, sin duda, de quienes tienen la pretensión de creer que la Historia, con mayúsculas, les pertenece. $\mathrm{Y}$ así insisten en que «no nos la robarán", en que todos los demás, menos ellos, la falsifican, en que están en condiciones de ofrecer, por ejemplo, sobre la entrevista de Hendaya entre Franco y Hitler el «punto finaln y, en definitiva, que pueden ofrecernos sobre la guerra civil "todos los problemas resueltos" ${ }^{18}$. Estos que acostumbran a poner "puntos finales" acaso asienten a las "soluciones finales»... De la Cierva ha publicado ya una "historia definitiva" de la guerra y ahora nos obsequia con una "esencial", que lo es seguramente porque resuelve todos los problemas... Pero es tan imposible una insensatez mayor un mayor cinismo mercantil como grave que estos libros se vendan bien, aunque no sepamos que se lean (no sabemos de nadie que los cite).

La Historia naturalmente no podrá sino tener por blasfemo a quien se atreve a decir que "La Ha Resuelto», dado que lo único que, pobres de nosotros, podemos hacer humildemente es intentar arrancarle un nuevo secreto cada día en la certeza de que siempre, siempre, nos velará alguno.

18 Estoy basándome para decir esto en dos títulos de ciertos y conocidos libros entre la abundantisima producción escrita del autor del que hablamos, incluido el que ahora comentamos.

Hisponia، LVIJ/2, núm. 196 (1997) 777-787 